International Journal of Instruction e-ISSN: 1308-1470 • www.e-iji.net

Article submission code 20210228185630

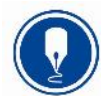

January $2022 \bullet$ Vol.15, No.1

p-ISSN: 1694-609X

pp. $891-910$

Received: 28/02/2021

Revision: 17/08/2021
Accepted: 13/09/2021

OnlineFirst: 06/12/202

\title{
Teacher's Achievement in Curriculum 2013 Training: A Hierarchical Linear Model
}

\author{
Junaidin \\ Correspondent author, Universitas Negeri Yogyakarta, Indonesia, \\ junaidin.2018@student.uny.ac.id
}

\section{Sugiyono}

Prof. Dr. M.Pd., Universitas Negeri Yogyakarta, Indonesia, sugiyono@uny.ac.id

\section{Yoyon Suryono}

Prof. Dr. MS., Universitas Negeri Yogyakarta, Indonesia, ysuryo@uny.ac.id

\section{Komalasari}

Central Kalimantan Province Education Quality Assurance Agency (LPMP), Ministry of Education and Culture, Indonesia, komalalpmpkalteng2015@gmail.com

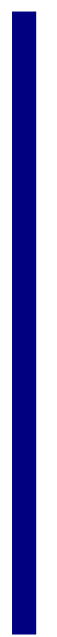

This study develops an Hierarchical Linear Model (HLM) model in order to identify the predictors that have an effect on teachers' achievement in curriculum 2013 training. It is a two-level model with teacher's characteristics as Level 1 variables and facilitators characteristics as Level 2 variables. The analysis in this study uses secondary data. The Indonesian Central Kalimantan Province Education Quality Assurance Institute has implemented education and training for the 2013 curriculum, and has a post test score document. The HLM analysis model is applied, with stages: zero model analysis, finalization of level-1, level-2, and final analysis model for teachers and facilitators. The results of the analysis for the teacher level, that the PRIA-B predictor has a direct positive effect on the results, $\mathrm{C} 13 \mathrm{ACH}$. Meanwhile, GENDER has a negative effect on $\mathrm{C} 13 \mathrm{ACH}$. The Facilitator, GENDER, and P_MEAN have a direct positive effect on C13ACH while GENDER is also found interacting with PRIAB that leads to the outcome variable, $\mathrm{C} 13 \mathrm{ACH}$. The interaction between GENDER and the slope of PRIAB is a positive one. The results of the model variance components indicate that the final full model explains about $46 \%$ of the total available variance.

Keywords: HLM, curriculum 2013, training, achievement, teachers, curriculum

\section{INTRODUCTION}

Since the 2013 Curriculum was established as a new policy product in the 2013/2014 school year, the management of education and training for teachers has been carried out

Citation: Junaidin., Sugiyono., Suryono, Y., \& Komalasari. (2022). Teacher's achievement in curriculum 2013 training: A hierarchical linear model. International Journal of Instruction, 15(1), 891910. https://doi.org/10.29333/iji.2022.15151a 
by the LPMP (Institute for Quality Assurance of Education) in every province, in Indonesia. The purpose of the training is to improve teacher competence, and prepare teachers to implement the 2013 Curriculum appropriately. In addition, training activities are to overcome teachers who are not competent enough. Some teachers are sometimes underestimated by community members, one of which is because of low teaching motivation (Gobena, 2018). The 2013 Curriculum training activities are intended as an effort to ensure teacher competence, while minimizing unfavorable opinions.

As program manager, LPMP organizes 2013 curriculum training for 800 high school teachers. The time of the activity is May 25-30 2017 in the province of Central Kalimantan. For six days or 39 hours, the trainees were trained in 20 schools as specified locations. The trainees are teachers of 18 subjects in high school. This form of training aims to overcome training experiences that have not contributed conceptually and practically to teacher self-development (Ayvaz-Tuncel and çobanoglu, 2018), including strengthening other approaches that promote teacher performance (bottom-up, collaborative, context-specific, and integrated) (Bergmark, 2020). The training pattern is expected to be more effective in ensuring the quality of teachers.

In particular, the objective of this training to improve the participants competence in: a) understanding the dynamics and policies of curriculum development, the policy of strengthening character education and the application of literacy in learning; $b$ ) analysing the learning objectives, material, learning, and assessment covered: Document: learning objectives and guidelines subjects, the material in textbooks, Implementation learning model, assessment of learning; c) designing the learning implementation plan with $21 \mathrm{st}$ century skill (critical thinking, creativity, communication, and collaboration); c) doing a Higher Order Thinking Skill (HOTS) learning practice and assessment and doing a review of the practice result; and d) practicing the process and reporting the assessment of learning and the introduction to e-raport application (Direktorat pembinaan sekolah menengah atas direktorat jenderal pendidikan dasar dan menengah kementerian pendidikan dan kebudayaan, 2017).

In accordance with the Guidelines, assessment methods of participants are using the following methods: 1) Assessment of attitude is done through the observation of the participants activities by the committee and the instructor including attendance, consistency obey the regulation, and activities in the classroom; 2) The assessment of material mastery is done through pre-test and post-test and observation of the discussion process; 4) Target teacher training, assessment of the results of the assignment is done through the fast sending of assigning tasks and the quality of task results.

This training uses a test post. Post test is a test conducted at the end of the training activity. The final test consists of 32 items, consisting of 30 multiple choice items, and 2 essays. Time to complete all items is 60 minutes. This test is an assessment to measure the mastery of the teacher's material on the 2013 curriculum. Thus, the success of the participants can be known. 
The main reason is that the data collected from these trainees is hierarchical. Teacher acquisition scores in the post-test can be predicted by applying the hierarchical linear model (HLM). For example, teachers are sampled as facilitators in their classrooms. Teacher and facilitator data were analyzed simultaneously in the level-1 and level-2 models, i.e. combining the appropriate predictors in the model. According to experts, such as Subedi, Swan and Hynes (2013), that this approach allows researchers to measure the value of variability and effects at level-2, and determine predictors.

This study aims to develop an HLM model to identify the predictors that have effect on teachers' gain scores on post-test of curriculum 2013 training. The teachers' gain scores on post-test of curriculum 2013 training in this study are termed as teachers' achievement in curriculum 2013 training. It is also important that using HLM could examine the interaction effects between teacher and facilitator level predictors on teachers' achievement in curriculum 2013 training. Whereas in the single-level model, cross-level interactions are ignored in the examination. Furthermore, this study employs the HLM technique in order to overcome or to minimize the bias caused by aggregation and /or disaggregation

The findings of this study will be valuable for policy makers and stakeholders of Educational Quality Assurance Central Kalimantan, an evaluation of the implementation of curriculum 2013 training for $X$ grade teachers in 2017.First, given the significant predictors of teachers' achievement in curriculum 2013 training. Second, given the recommendation for policy-based evidence regarding curriculum 2013 training for teachers in Central Kalimantan Indonesia.

The purpose of this study is:

1. To develop an HLM model in order to identify the predictors that have effect on teachers' achievement in curriculum 2013 training.

2. To discuss the finding from the Hierarchical Linear Modelling technique on teachers-, and facilitator-level variables and their impact on teacher's achievement in curriculum 2013 training.

3. To examine the cross-level interaction (teachers- and facilitators-level) on teacher's achievement in curriculum 2013 training.

4. To determine the percentages of the variance explained of total available variance for finalfull model.

It is a two-level model with teachers characteristics as Level 1 variables and facilitators characteristics as Level 2 variables.The following research questions are answered through this study:

1. What teachers-level variables are significant predictors of teacher's achievement in curriculum 2013 training?

2. What facilitators-level variables are significant predictors of teacher's achievement in curriculum 2013 training? 
3. What cross-level interaction variables (teachers- and facilitators-level) are significant of teacher's achievement in curriculum 2013 training?

4. What are the percentages of the variance explained of total available variance for final models?

\section{LITERATURE REVIEW}

Hierarchical Linear Model (HLM)

Hierarchical Linear Modeling (HLM) can be interpreted as a complex form of ordinary least squares regression (OLS). Where the use is to analyze the variance in the outcome variables, especially when the predictor variables are at various hierarchical levels (Woltman et al., 2012). Woltman further illustrates, that students in the class share the variance according to their general teacher and general class. In In relation to activities measuring school effects, HLM is one of the analytical techniques such as multivariate regression which was developed specifically to measure school effects. In addition, HLM allows to examine multi-level associations (Adcock and Phillips, 2001), such as students in schools, i.e predicting linear equations simultaneously at the student level in the school context, as well as between school levels between schools.

HLM can be ideally suited for the analysis of nested data because it identifies the relationship between predictor and outcome variables, by taking both level-1 and level-2 regression relationships into account. In addition to HLM's ability to assess cross-level data relationships and accurately disentangle the effects of between- and within-group variance, it is also a preferred method for nested data because it requires fewer assumptions to be met than other statistical methods (Raudenbush \& Bryk, 2002).

On a larger scale, HLM can be used for 3 other functions. First, HLM allows examination of aggregation bias in the context of aggregation bias error. Second, HLM does not work based on case-independent assumptions, so the problem of standard errors can be avoided, and Third, HLM can solve the problem of case heterogeneity, where multi-level procedures allow investigation of clustering effects (Munoz, Prather and Stronge, 2011). Such an HLM framework can be applied in the analysis of this research data.

HLM has grown much wider. Raudenbush and Bryk, (2002) mention that several domains (education, health, social work, and business) have passed. Its widespread use resulted in the designation being changed, mainly because of the simultaneous development of methods in statistics. Its changing designations (multi-level, mixed-level, mixed-linear, mixed-effect, random-effects, random coefficient (regression), and (complex) covariance component modeling), indicate that HLM has been an effective statistical solution.

Behind its advantages, HLM turns out to require a large sample size, especially in detecting effects at level-1. Another limitation is that it can only deal with missing data at level-1, and remove groups with missing data, especially when those data are at level2 , and/or higher. Both of these reasons can be overcome by increasing the number of groups rather than the number of observations per group. In Hofmann, (1997) report, that 
thirty groups with thirty observations per group is equal to one hundred and fifty groups with 5 observations each. This characteristic of HLM is another reason to be used in this research.

\section{CURRICULUM 2013 TRAINING}

Training as a strategy to increase human resources is not without purpose. Some experts explain the various goals, such as familiarizing self-reflection, improving practical and theory-based actions, teaching students, influencing students to learn, realizing professional responsibilities, guaranteeing certain values, and trying to cultivate a safe learning environment (Stephens, Tønnessen and Kyriacou, 2004). Several reasons given by Stephens, Tønnessen and Kyriacou were the reasons for the 2013 Curriculum training.

In the 2013 Curriculum training, subject teachers and counseling guidance teachers were involved to understand the management of learning in accordance with the objectives of the 2013 curriculum. The 2013 curriculum training was carried out until the 2017/2018 school year. In addition to training, this policy also provides mentoring programs that aim to strengthen the implementation of the 2013 curriculum. In mentoring, the use of learning media is applied directly, such as the use of videos, case studies, computers, and other relevant reading materials (do Amaral and Fregni, 2021). The training and mentoring involving 4,501 SMA is expected to be able to guarantee the quality of graduates in accordance with the training objectives, especially the national education goals.

Technically, the 2013 curriculum training pattern by LPMP uses the following strategies: 1) The aim is to improve learning and assessment technical skills, so that teachers are able to implement the 2013 curriculum concept; 2) Implementation time is 6 days, or the equivalent of 39 hours @ 60 minutes, from April to 4 June 2017; 3) The place of implementation is the selected SMA or cluster, taking into account the characteristics of the region and the prevailing funding pattern. The school-based training pattern actually brings the training program closer to teacher professional development efforts that are based on contextual (Suciati et al., 2019), and student-centered learning (Hwang, 2020). This curriculum training technique includes a nationally applicable pattern.

The human resources involved in the training consisted of trainers/instructors/resource persons who had participated in the refresher program by the Directorate and LPMP in 2017. The number of training participants was 85,610 teachers. This amount is adjusted to the quota and budget provided. In addition, participants are representatives of 18 subject teachers at the target high schools, and participants are prioritized who have attended 2013 curriculum training at various levels. Other criteria are having skills to operate Microsoft Office programs (Word, Excel, Power Point), have a good track record, communication skills, and explain training materials well. A number of these criteria were determined in an effort to ensure the achievement of the training objectives.

Another substance that is considered in the selection of training participants is the psychological aspect. In addition to external factors, this training takes into account psychosocial aspects, age, education level, and years of service (Odebode, 2018), as well 
as the ability to cooperate with colleagues (Ismail et al., 2018). Some of these considerations become important to be calculated in order to ensure the effectiveness of the training, and its results.

\section{METHOD}

The data used in writing this article is the post-test result data. The post-test data has been tested on 711 class X teachers, namely those who have attended the 2013 curriculum training in 2017. Thus, the data analyzed in this paper is secondary data. Ethically, the author asks for permission to use it from the leadership of LPMP. The use of secondary data that meets ethical requirements can be justified in the world of research, especially in building policy, conceptual, and practical contributions.

Data on teacher achievement in 2013 curriculum training, a series of tiered regression analysis was conducted using HLM 6. The analysis activity focused on the influence of several teacher and facilitator variables on one dependent variable. The dependent variable in this case is the teacher's achievement in the 2013 curriculum training, which is in the form of post-test scores. In analytical practice, level-1 is defined as the teacher level, and level-2 is the training level facilitator. Setting the level is intended to organize the analysis process in accordance with the characteristics of the HLM.

The analysis follows the HLM-appropriate step, for which we use a finite maximum estimate in all models. The first step is to estimate the unconditional model (zero model). This makes it possible to know the variability across sites in terms of profits. The second is estimating the level-1 model, and finally estimating the level- 2 model, and producing an estimate of cross-level interactions, both teachers and facilitators, on teacher achievement as an outcome variable. All steps are met to ensure that the process and results of the analysis will contribute to the various aspects of the research contribution.

\section{Variable in the Two-level Mode}


Table 1

List the teacher-level (level 1) variables, and the teacher-level (level-2) variables that are examined in this study.

\begin{tabular}{lll}
\hline Variable Name & Variable Label & Description \\
\hline Facilitator-level variables & Gender & Facilitator's gender \\
\hline GENDER & Age & Facilitator's age \\
\hline AGE & Experience & $\begin{array}{l}\text { Years of work as teachers for training } \\
\text { facilitator }\end{array}$ \\
\hline EXP & Education & Academic qualifications \\
\hline EDU & Average of Experience & $\begin{array}{l}\text { average of teachers experience for every } \\
\text { facilitator }\end{array}$ \\
\hline EXP_AGE & Average of age & average of teachers age for every facilitator \\
\hline GEN MEAN & Average of gender & $\begin{array}{l}\text { average of teachers gender for every } \\
\text { facilitator }\end{array}$ \\
\hline P MEAN & Average of prior ability & $\begin{array}{l}\text { average of teachers prior ability for every } \\
\text { facilitator }\end{array}$ \\
\hline Teacher-level variables & Experience & Years of work as teachers \\
\hline EXP & Age & Teacher's age \\
\hline AGE & Gender & Teacher's gender \\
\hline GENDER & Religion Class & $\begin{array}{l}\text { Class for religion teachers in curriculum } \\
\text { 2013 training }\end{array}$ \\
\hline CA & Language Class & $\begin{array}{l}\text { Class for language teachers in curriculum } \\
\text { 2013 training }\end{array}$ \\
\hline CB & Social Class & $\begin{array}{l}\text { Class for social teachers in curriculum 2013 } \\
\text { training }\end{array}$ \\
\hline CS & Math and Science Class & $\begin{array}{l}\text { Class for Math and Science teachers in } \\
\text { curriculum 2013 training }\end{array}$ \\
\hline CM & Prior ability & $\begin{array}{l}\text { Teachers' gain scores on pre test in } \\
\text { curriculum 2013 training }\end{array}$ \\
\hline PRIAB & $\begin{array}{l}\text { Teachers' gain scores on pre test in } \\
\text { training }\end{array}$ & $\begin{array}{l}\text { curriculum 2013 training } \\
\text { C13ACH }\end{array}$ \\
\hline
\end{tabular}

To carry out the HLM analysis, two sets of variables at teacher-, and facilitator-level need to be specified. The conceptual model for the two-level model of factors influencing teachers' achievement in curriculum 2013 training is shown in figure 1. 


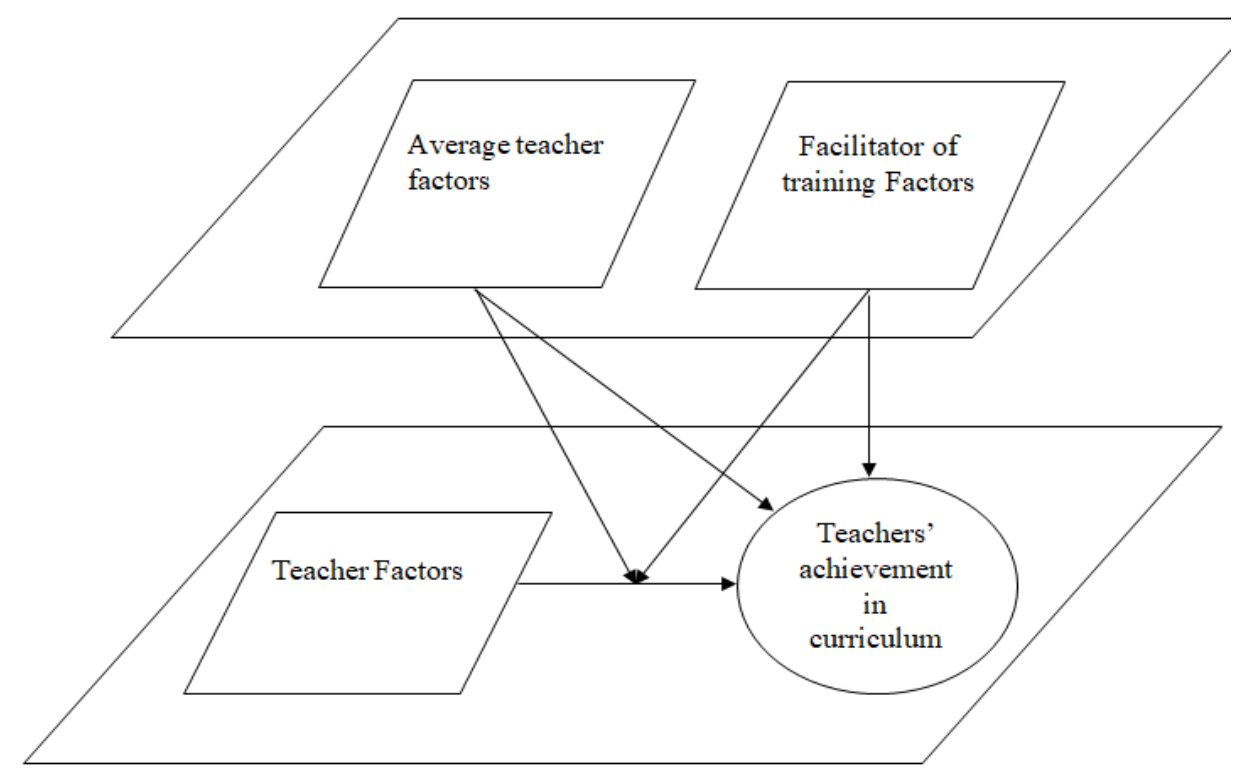

Figure 1

Two-level model of Teachers' achievement in curriculum 2013 training

\section{FINDINGS AND DISCUSSION}

As explained earlier in this introduction, the two-level HLM analysis is carried out to examine the relationship between level-1 and level-2 predictors and the outcome variable in the model. It should be noted that in this section, the term level- and teacher-level are used interchangeably. Similarly, level-2 and facilitator-level are also used interchangeably.

The description of the findings and discussion in this paper is based on the formulation of the problem, and especially the research questions. The application of 2-level HLM analysis was carried out primarily to examine the relationship between level-1 and level2 predictors, as well as outcome variables in the model. We also need to emphasize that the use of terms will appear interchangeably, for example the terms teacher level and level, the term level-2 and facilitator level. Findings and discussions can be seen in the following sections.

\section{The Hypothesised Model}

Figure 2 presents the hypothesised two-level model of teachers' achievement in curriculum 2013 training. It was proposed that variables in the presage are the 8 facilitator-level variables, and 8 teachers-level variables. 


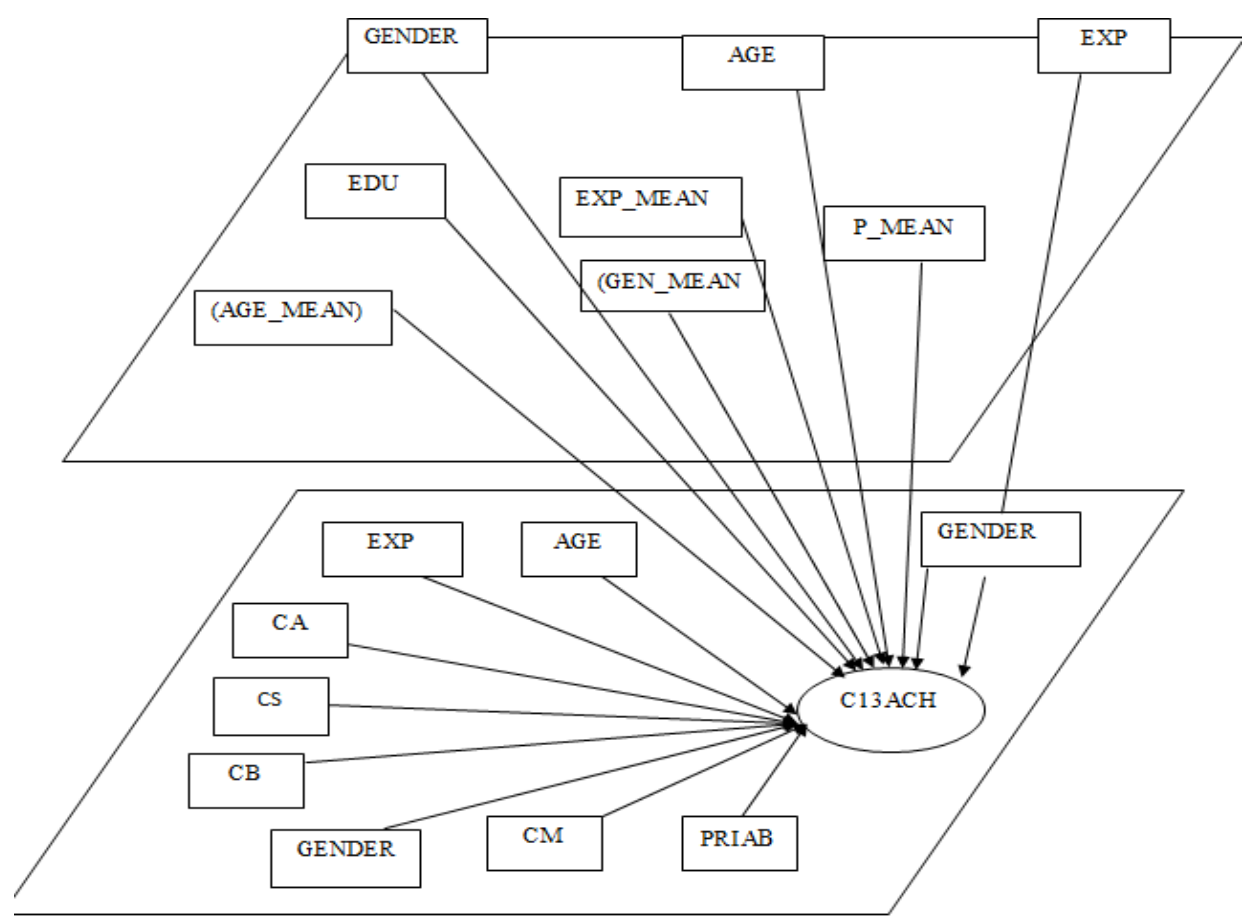

Figure 2

The hypothesised two-level model of Teachers' achievement in curriculum 2013 training

The facilitator-level variables in the presage phase include Facilitators' gender (GENDER), age (AGE), years of teaching experiences (EXP), academic qualification (EDU), average of teachers experience for every facilitator (EXP_MEAN), average of teachers age for every facilitator (AGE_MEAN), average of teachers gender for every facilitator (GEN_MEAN) and average of teachers prior ability for every facilitator (P_MEAN).

The teachers-level variable in the presage stage includes year of teaching (EXP), teachers' age (AGE), teachers' gender (GENDER), religion class (CA), language class (CB), social class (CS), Math and science class, (CM), and prior ability of teacher (PRIAB). The proposed variable in the product stage is teacher's achievement in curriculum 2013 training $(\mathrm{C} 13 \mathrm{ACH})$.

\section{The Null Model}

An examination of the null model initiates the analysis of the HLM model. Understanding in advance the unconditional model is intended to get an estimate of the amount of available variance, which is described in the model. Predictors at the teacher and facilitator levels were ignored, so predictors at various levels were not found in the model. 
In the null model, some variation in the outcome variable (ie $\mathrm{C} 13 \mathrm{ACH}$ ) is represented. The description of the results is allocated to two different levels, namely the level of the teacher and the facilitator. This method allows partitioning of the variance in the result variable to two levels. The zero model in question is determined by the following equation.

Level-1 model: $\mathrm{C} 13 \mathrm{ACH}$ for each teacher is modelled as a function of teacher mean plus a random error.

$Y i j=\beta 0 j+R i j$

Where

$\mathrm{Y}_{\mathrm{ijk}}$ is the teacher is teacher's achievement in curriculum 2013 training $(\mathrm{C} 13 \mathrm{ACH})$ under facilitator $\mathrm{j}$;

$\beta 0 j$ is the intercept or mean teacher's achievement in curriculum 2013 training under facilitator $\mathrm{j}$; and

$R i j$ is a random 'teacher effect' or error (i.e. the deviation of teacher i under facilitator j's score from the mean teacher's achievement in curriculum 2013 training under facilitator j.

Based on the above equation, the level of teacher achievement is below facilitator $\mathrm{j}$, which is considered equal to the teacher's average, and is added with random errors. The assumption used is his opinion Raudenbush and Bryk, (2002), that each level-1 error, Rjk, is normally distributed, with a mean of zero, and a constant level-1 variance, which is 2 .

Level-2 model: $\beta_{0}=\gamma_{00}+\mathrm{U} 0$

Where:

$\beta_{0}$ is the intercept or mean teacher's achievement in curriculum 2013 training;

$\gamma_{00}$ is the overall mean of teacher's achievement in curriculum 2013 training across facilitator: and

U0 is the random 'facilitator effect" or error (i.e., the deviation of facilitator $\mathrm{j}$ means from the grand mean.

The $\sigma^{2}$ parameter represents the teacher-level variability, while the $\tau \pi$ parameter represents the facilitator-level variability. The zero-in-facilitator and among-facilitator model allows for estimating the following proportions of variance:

$\frac{\sigma^{2}}{\sigma^{2}+\tau_{\pi}}$ is the proportion of variance within facilitators;

$\frac{\tau_{\pi}}{\sigma^{2}+\tau_{\pi}}$ is the proportion of variance among facilitators.

The reliability of the least square estimates coefficients at one level: the facilitator. 
Table 2

The null model results: Two-level model of teacher's achievement in curriculum 2013 training

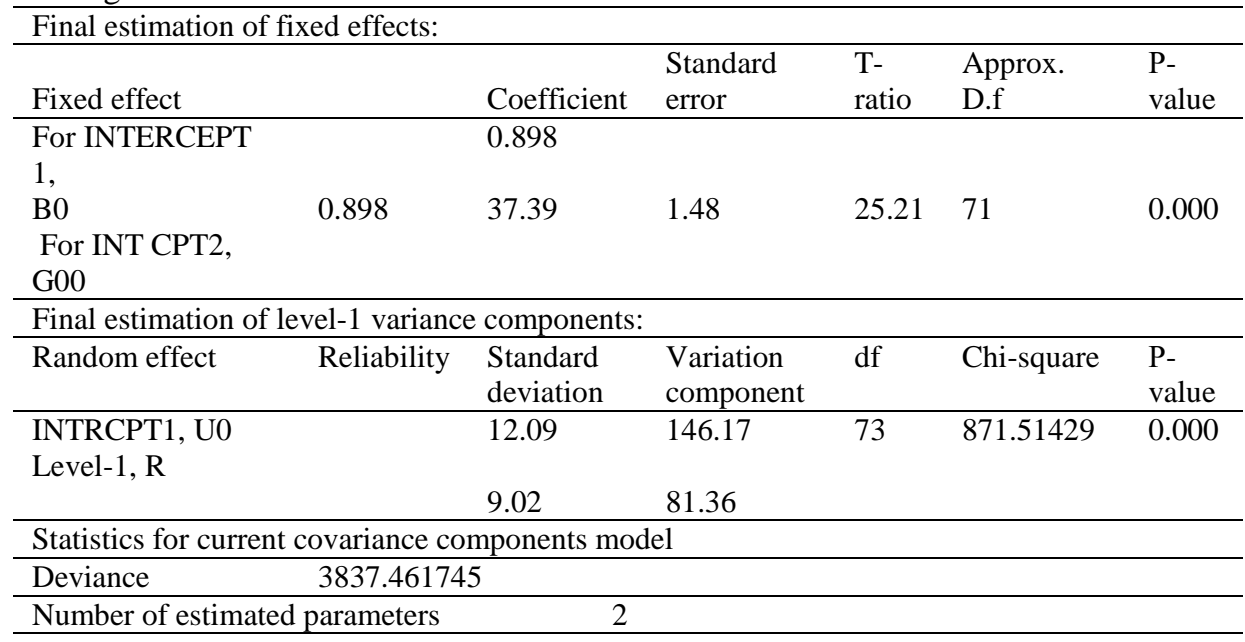

Understanding the results of HLM analysis, the model is completely unconditional. Table 2 shows that the estimation of the proportion of variance can be done for two levels using the following equation.

At level 1

$\frac{\sigma^{2}}{\sigma^{2}+\tau_{\pi}}=\frac{81.36}{81.36+146.17}=0.36$

At level 2

$\frac{\tau_{\pi}}{\sigma^{2}+\tau_{\pi}}=\frac{146.17}{81.36+146.17}=0.64$

In terms of teacher achievement for 2013 curriculum training, the contribution of the two variables (teacher level and facilitator level) differed in value, 36\% and $64 \%$, respectively. As explained by Raudenbush and Bryk, (2002), that each reliability value decreases by 0.05 , it is assumed that there is no random effect on certain coefficients. In Table 2 , the reliability values at level- 1 and level-2 are more than 0.05 . This explains that there is a random effect on teacher achievement in activities managed by LPMP, 2013 curriculum training. Finally, analyzes to test the conditional model and construct the final model were carried out.

\section{The Final Model}

In determining the level-1 model, several variables that were found to have an effect on teacher achievement in the 2013 curriculum training, such as the level of teachers in the HLM 6 analysis, were entered into the equation one by one, according to the magnitude and statistical significance of the path coefficient, and the steps started from the path strongest to the weakest. At this phase, level- 2 predictors have not been included as 
suggested by Raudenbush. The aim is to test how much variance can be explained by a level-1 predictor. In the event that the examination results and the coefficients obtained are not significant, they are removed from the model and the potential variables are then entered into the equation. This step is repeated until the final level-1 model has a significant effect.

After the level-1 variable is solved, the facilitator level variable is entered into the equation. This exploration is carried out with the aim of examining the possibility of each level-2 variable to be included in the model. The steps are to enter one by one the facilitator level variables according to their t-value (see the results of exploratory analysis). This step is done repeatedly, until a level-2 model with only significant effects on level-1 and level-2 is obtained. This final model uses the following equation:

Level-1 Model

$\mathrm{Y}=\beta_{0}+\beta_{1} *($ GENDER $)+\beta_{2} *(\mathrm{PRIAB})+\mathrm{R}$

Level-2 Model

$\beta_{0}=\gamma_{00}+\gamma_{01} *($ GENDER $)+\gamma_{02} *\left(P_{-}\right.$MEAN $)+U_{0}$

$\beta 1=\gamma 10+\mathrm{U} 1$

$\beta_{2}=\gamma_{20}+\gamma_{21} *($ GENDER $)+\mathrm{U} 2$

The final model represented by the following equation is obtained after substituting the equation at level-2 into the level-1 equation:

$\mathrm{Y}=\gamma_{00}+\gamma_{01} *($ GENDER $)+\gamma_{02} *\left(\mathrm{P} \_\right.$MEAN $)+\gamma_{10} *($ GENDER $)+\gamma_{20} *(\mathrm{PRIAB})+$ $\gamma_{21} *($ GENDER $) *($ PRIAB $)+\mathrm{U} 0+\mathrm{U} 1 *$ GENDER + U2 $*$ PRIAB + R

The overall intercept function (G00), four main effects, one cross-level interaction effect and random error (U0 + U1* GENDER + U2* PRIVATE $+\mathrm{R}$ ) are constructions of the above equation, where teacher achievement in the 2013 curriculum training is described. The four effects include the direct effects from teachers' gender (GENDER), prior ability of teacher (PRIAB), Facilitators' gender (GENDER), and average of teachers prior ability for every class (P_MEAN).

The cross-level interaction effects include Facilitators' gender (GENDER) on prior ability of teacher (PRIAB). Table-5 shows the results of the final two-level model of teacher's achievement in curriculum 2013 training. The relationships of the direct and in interaction effects can be seen in figure 3.

The Effects of Level-1 and Level-2 Predictors on teacher's achievement in curriculum 2013 training

In Table 3, and Figure 3, the outcome variable $(\mathrm{C} 13 \mathrm{ACH})$ is directly affected by two variables at level-1, and two variables at level-2. These variables include GENDER, and PRIAB, at level-1 and GENDER), and average of teachers prior ability for every class (P_MEAN) at level-2. The positif direct effects of PRIAB $(\gamma=0.26)$ on $\mathrm{C} 13 \mathrm{ACH}$ suggest 
that the higher the score of teachers' prior ability, and the higher their achievement in curriculum 2013 training. The negatif direct effect of GENDER $(\gamma=-2.89)$ implies that female teachers tend to have better achievement in curriculum 2013 training than male teachers. A meta-analysis study by Orakei, Aktan, Toraman, \& Cevik, (2016) that female gender and special education training did not affect teacher attitudes towards inclusive education.

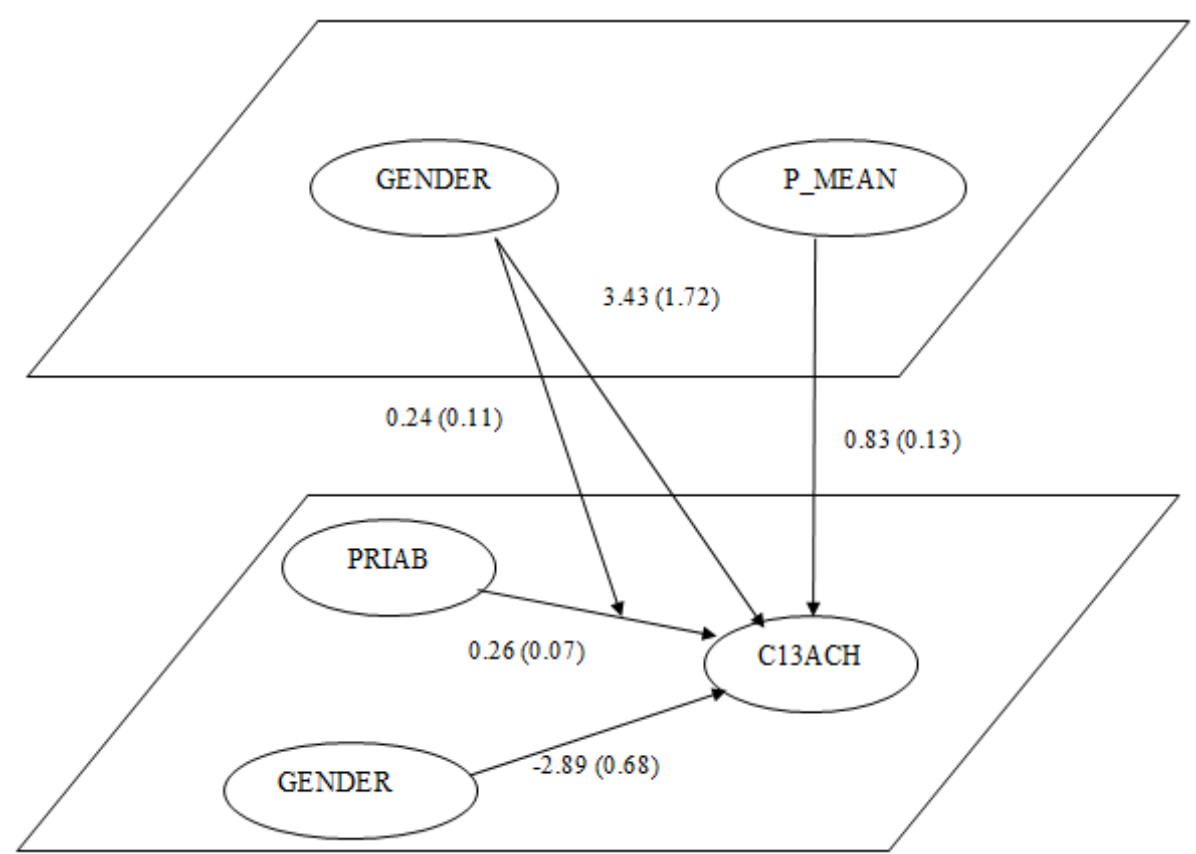

Figure 3

The final two-level model for teacher's achievement in curriculum 2013 training

For level-2, GENDER $(\gamma=3.43)$ yields a positive direct effect on $\mathrm{C} 13 \mathrm{ACH}$. This suggests that the teachers with male facilitators tend to have better achievement in curriculum 2013 training than teachers with female facilitators. Furthermore, P_MEAN $(\gamma=0.83)$ yields a positive direct effect on $\mathrm{C} 13 \mathrm{ACH}$, indicating that the higher average score of prior ability of teachers, the higher their achievement in curriculum 2013 training. 
Table 3

The final Model Results: Two-level Model of Teacher Achievement in Curriculum 2013 Training

\begin{tabular}{|c|c|c|c|c|c|}
\hline \multicolumn{6}{|l|}{ Final estimation of fixed effects: } \\
\hline Fixed effect & Coefficient & $\begin{array}{l}\text { Standard } \\
\text { error }\end{array}$ & $\begin{array}{l}\mathrm{T}- \\
\text { ratio }\end{array}$ & $\begin{array}{l}\text { Approx. } \\
\text { D.f }\end{array}$ & P-value \\
\hline \multicolumn{6}{|l|}{ For $\quad$ INTRCPT1, $\beta_{0}$} \\
\hline INTRCPT2, $\gamma_{00}$ & 37.12 & 1.14 & 32.648 & 71 & 0.000 \\
\hline GENDER, $\gamma_{01}$ & 3.43 & 1.72 & 1.996 & 71 & 0.049 \\
\hline P_MEAN, $\gamma_{02}$ & 0.83 & 0.13 & 6.406 & 71 & 0.000 \\
\hline \multicolumn{6}{|l|}{ For GENDER slope, $\beta_{1}$} \\
\hline INTRCPT $2, \gamma_{10}$ & -2.89 & 0.68 & -4.232 & 73 & 0.000 \\
\hline \multicolumn{6}{|l|}{ For $\quad$ PRIAB slope, $\beta_{2}$} \\
\hline INTRCPT2, $\gamma_{20}$ & 0.28 & 0.07 & 3.911 & 72 & 0.000 \\
\hline GENDER, $\gamma_{21}$ & 0.24 & 0.12 & 2.161 & 72 & 0.034 \\
\hline \multicolumn{6}{|c|}{ Final estimation of level-1 and level-2 variance components: } \\
\hline Random effect $\quad$ Reliability & SD & $\begin{array}{l}\text { Variance } \\
\text { Component }\end{array}$ & df & $\begin{array}{l}\text { Chi- } \\
\text { square }\end{array}$ & $\begin{array}{l}\mathrm{P} \\
\text { value }\end{array}$ \\
\hline INTRCPT1, U0 & 7.52 & 56.50 & 57 & 247.68 & 0.000 \\
\hline GENDER slope, U1 & 2.18 & 4.77 & 59 & 58.71 & $>.500$ \\
\hline PRIAB slope, U2 & 0.20 & 0.04 & 58 & 111.77 & 0.000 \\
\hline level-1, $\mathrm{R}$ & 8.13 & 66.13 & & & \\
\hline \multicolumn{6}{|c|}{ Statistics for current covariance component model } \\
\hline Deviance $\quad=3692.575$ & & & & & \\
\hline
\end{tabular}

\section{The Interaction Effects}

In addition to estimating the main effects as presented previously, the results of HLM 6 also explain the interaction effect between predictors and outcome variables at the teacher level, namely GENDER at the facilitator level, which affects the slope of PRIAB at level1.

In terms of cross-level interactions, variables (GENDER and PRIVATE) are involved in $\mathrm{C} 13 \mathrm{ACH}$. The two predictor variables, namely GENDER and PRIAB, the final equation after keeping the other variables constant or zero, are:

$\mathrm{Y}_{\mathrm{ij}}=\gamma_{00}+\gamma_{01} *($ GENDER $)+\gamma_{20} *(\mathrm{PRIAB})+\gamma_{21} *($ GENDER $) *($ PRIAB $)+\mathrm{R}_{\mathrm{ij}}$

$\gamma_{00}$ represents the average of teachers' achievement in curriculum 2013 training across facilitators, in this analysis, it is $37.11 ; \gamma_{01}=3.43$; and $\gamma_{20}=0.28$; and $\gamma_{21}=0.24$. This has resulted in the following equation:

$\mathrm{Y}_{\mathrm{ij}}=37.11+3.43 *($ GENDER $)+0.28 *($ PRIAB $)+0.24 *($ GENDER $) *($ PRIAB $)+\mathrm{R}_{\mathrm{ij}}$

The equations presented can be used to calculate facilitator-level coordinates, in order to obtain a graphical representation of the effects of cross-level interactions. The facilitator will calculate the coordinates in terms of: 
1. One standard deviation below the average on PRIAB and GENDER (female).

2. One standard deviation below the average on PRIAB and GENDER (male).

3. One standard deviation above the average on PRIAB and GENDER (female).

4. One standard deviation above the average the average on PRIAB and GENDER (male).

5. Average on PRIAB and GENDER (female).

6. Average on PRIAB and GENDER (male).

The calculation for the coordinates using the equation:

$\mathrm{Y}_{\mathrm{ij}}=37.11+3.43 *($ GENDER $)+0.28 *(\mathrm{PRIAB})+0.24 *($ GENDER $) *(\mathrm{PRIAB})+\mathrm{R}_{\mathrm{ij}}$

Therefore, the coordinates are:

1. Low prior ability teachers and female teachers (PRIAB $=-11.2$; GENDER $=0)$; $\mathrm{Y}$ (teachers' achievement in curriculum 2013 training $)=37.11+3.43(0)+0.28 *(-$ $11.2)+0.24(0)(-11.2)=33.97$

2. Low prior ability teachers and male teachers (PRIAB $=-11.2$; GENDER $=0$ ); $\mathrm{Y}$ (teachers' achievement in curriculum 2013 training $)=37.11+3.43(1)+0.28 *(-$ $11.2)+0.24(1)(-11.2)=34.72$

3. High prior ability teachers and female teachers $($ PRIAB $=11.2$; GENDER $=0)$; $Y$ (teachers' achievement in curriculum 2013 training) $=37.11+3.43$ $(0)+0.28 *(11.2)+0.24(0)(11.2)=40.25$

4. High prior ability teachers and male teachers $(\mathrm{PRIAB}=11.2$; GENDER $=1) ; \mathrm{Y}$ (teachers' achievement in curriculum 2013 training) $=37.11+3.43$ $(1)+0.28 *(11.2)+0.24(1)(11.2)=46.36$

5. Average prior ability teachers and female teachers $(\mathrm{PRIAB}=0$; GENDER $=0$ ); $Y$ (teachers' achievement in curriculum 2013 training) $=37.11+3.43$ $(0)+0.28 *(0)+0.24(0)(0)=37.11$

6. Average prior ability teachers and male teachers $(\mathrm{PRIAB}=0$; GENDER $=1)$; $\mathrm{Y}$ (teachers' achievement in curriculum 2013 training) $=37.11+3.43$ (1) $+0.28 *(0)+0.24(1)(0)=40.54$ 
Tabel 4

The calculation for the coordinates

\begin{tabular}{|c|c|c|c|c|}
\hline & & \multirow{3}{*}{ SD } & \multicolumn{2}{|l|}{ Gender } \\
\hline & & & 0 & 1 \\
\hline & & & Female & Male \\
\hline \multirow{3}{*}{$\begin{array}{l}\text { Prior Ability } \\
\text { (PRIAB) }\end{array}$} & Low & -11.2 & 33.97 & 34.72 \\
\hline & Average & 0 & 37.11 & 40.54 \\
\hline & High & 11.2 & 40.25 & 46.36 \\
\hline
\end{tabular}

The results are presented in Table 4, indicate that gender of facilitator (GENDER) interacts with teachers' prior ability (PRIAB) with an interaction effect coefficient of 0.24 , suggesting that the gender of facilitator has a positive effect on the slope of teachers prior ability that leads to the outcome variable, teachers' achievement in curriculum 2013 training $(\mathrm{C} 13 \mathrm{ACH})$.

Figure 4 shows the interaction effect of GENDER on PRIAB on $\mathrm{C} 13 \mathrm{ACH}$, with the effects vary according to gender of facilitators. As shown in Figure 10.5.1, teachers facilitated by a male facilitator in class of curriculum 2013 training, the positive effects of teachers' prior ability on their achievement in curriculum 2013 training is stronger, while teachers facilitated by a female facilitator in class of curriculum 2013 training, the positive effects of teachers' prior ability on their achievement in curriculum 2013 training is weaker.

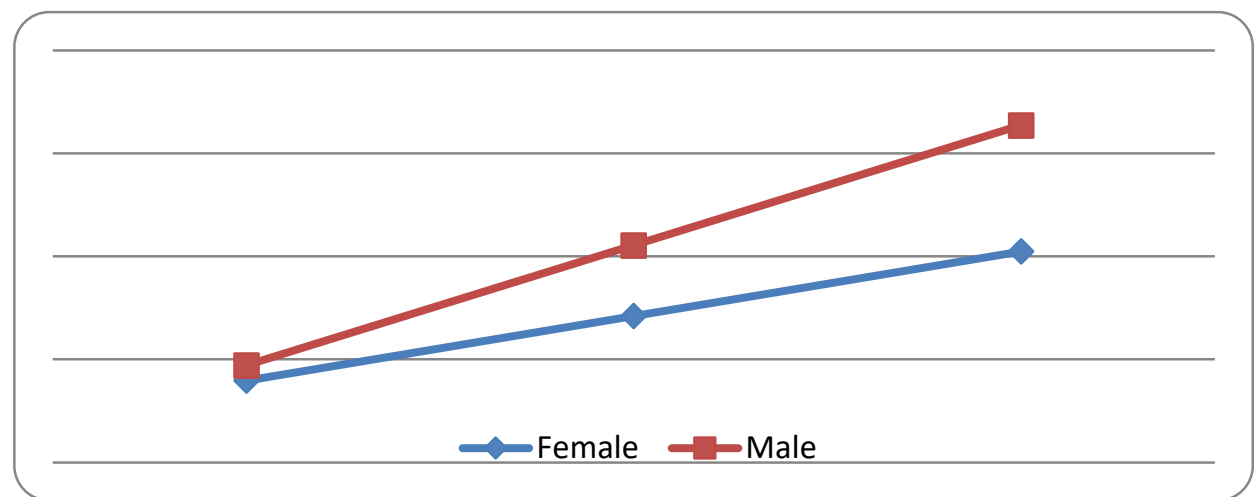

Figure 4

The cross-level interaction effect of facilitators' gender on the slope of teacher's prior ability on teachers' achievement in curriculum 2013 training

\section{Variance Explained for the Two-level Model}

In addition, HLM can provide additional information regarding the variance component in the model. In this case, the variance component needs to be detected to understand the proportion of variance explained by the two levels. The variance component estimation for the outcome variable, in the form of teacher achievement in training, is presented in Table 5. 
The largest probability distribution was found at the facilitator level (64\%), followed by $36 \%$ at the teacher level. The final model estimated by the variance component describes the extent to which the variance decreases as a result of the inclusion of the predictor at the two levels. In Table 5, the final model explains most of the variance at level-2 (61\%), which is only represented by $64 \%$ of the overall variance available to be explained by the facilitator level. As for the teacher level, where $19 \%$ of the variance is explained by the model. Similarly, the teacher level is only represented by $36 \%$ of the overall variance available to be explained by this level.

Table 5

Estimation of variance components: Teachers' achievement in curriculum 2013

Training

\begin{tabular}{|c|c|c|}
\hline \multirow[t]{2}{*}{ Model } & \multicolumn{2}{|c|}{ Estimation of variance components } \\
\hline & $\begin{array}{l}\text { Between teachers } \\
(\mathrm{n}=506)\end{array}$ & $\begin{array}{l}\text { Between facilitators } \\
(\mathrm{n}=74)\end{array}$ \\
\hline Fully unconditional model & 81.36 & 146.17 \\
\hline Final Model & 66.13 & 56.50 \\
\hline \multicolumn{3}{|l|}{ Variance at each level } \\
\hline Between teachers & \multicolumn{2}{|c|}{$81.36 /(81.36+146.17)=0.36=36 \%$} \\
\hline Between facilitators & \multicolumn{2}{|c|}{$146.17 /(81.36+146.17)=0.64=64 \%$} \\
\hline \multicolumn{3}{|c|}{$\begin{array}{l}\text { Proportion of variance explained } \\
\text { by final model }\end{array}$} \\
\hline Between teachers & \multicolumn{2}{|c|}{$(81.36-66.13) / 81.36=0.19=19 \%$} \\
\hline Between facilitators & \multicolumn{2}{|c|}{$(146.17-56.5) / 146.17=0.61=61 \%$} \\
\hline $\begin{array}{l}\text { Proportion of total variance } \\
(0.19 \times 0.36)+(0.61 \times 0.64\end{array}$ & $\begin{array}{l}\text { by final model } \\
46 \%\end{array}$ & \\
\hline
\end{tabular}

Overall, $46 \%$ of the total available variance is explained by the final model at both levels. While the standard deviation of the final model is reduced by 144.89 compared to the zero model deviation, with an additional 5 degrees of freedom. Based on the explanation of Bryk and Raudenbush, if the ratio of decreasing deviation with increasing degrees of freedom is greater than 1 , then the final model is considered to be better than the null model.

\section{CONCLUSION}

This research presents two levels of teacher achievement in the 2013 Curriculum training. Data analysis with HLM is carried out because this model allows analysis of the influence of the hierarchical structure on teacher achievement in training. In practice, HLM analysis begins with the analysis of the zero model, followed by the finalization of level-1, level2 , and finally the analysis of the final model consisting of the teacher level and the facilitator level.

The results of the analysis at the teachers-level show that the predictor of PRIAB is found to have a direct positive effect on the outcome variable, $\mathrm{C} 13 \mathrm{ACH}$. The results also indicate that GENDER is found to have a negative effect on $\mathrm{C} 13 \mathrm{ACH}$. At the facilitator level, GENDER and P_MEAN are found to have a direct positive effect on $\mathrm{C} 13 \mathrm{ACH}$ 
while GENDER is also found interacting with PRIAB that leads to the outcome variable, $\mathrm{C} 13 \mathrm{ACH}$. The interaction between GENDER and the slope of PRIAB is a positive one.

The model component variance results show that the final complete model explains about $46 \%$ of the total available variance. The total variance is described by HLM. The effect of two levels on the outcome variable, namely teacher performance in training, can be explained efficiently and effectively by HLM. The use of HLM in understanding various influencing factors in one activity can be applied in other research.

\section{IMPLICATION}

The findings of this study imply that the initial ability of teachers and gender (female) of teachers are important factors for predicting teacher achievement in the 2013 curriculum training. Substantially, the success of a training does not only depend on the average initial ability of the participants, in this case the teacher. Conceptual implications, such as the gender of the facilitator, in this case, come into play.

In terms of policy, the research provides information on the results of the 2013 curriculum training evaluation at that time, especially identifying predictors that affect teacher achievement in training. Practically, curriculum training programs for (both 2013 curriculum and other curricula), need to direct facilitators to be aware of, as well as encourage male teachers to be actively involved in training. In addition, the 2013 Curriculum training program and its mentoring activities in each school need to provide specific strategies to encourage male teachers to implement the 2013 Curriculum effectively.

Another policy implication is that the competence of female facilitators is further enhanced in the next training period, particularly in the mentoring program at the school level. Furthermore, program managers at the LPMP level should prepare better training and mentoring activities, and monitoring and evaluation of facilitator performance should be carried out on an ongoing basis for conceptual and practical purposes. In another conceptual aspect, researchers interested in this area could replicate similar predictive models using HLM, specifically to measure teacher performance in training elsewhere.

\section{REFERENCES}

Adcock, E. P. and Phillips, G. W. (2001) 'Measuring School Effects With Hierarchical Linear Modeling: Data Handling and Modeling Issues', Multiple Linear Regression Viewpoints, 24, pp. 1-10. Available at: papers3://publication/uuid/EFC0E83D-47894D63-B8AF-E71A66CC38A7.

do Amaral, J. A. A. and Fregni, F. (2021) 'Fostering system thinking learning by combining problem-based learning and simulation-based learning approaches', International Journal of Instruction, 14(3), pp. 1-16. doi: 10.29333/iji.2021.1431a.

Ayvaz-Tuncel, Z. and çobanoglu, F. (2018) 'In-service teacher training: Problems of the teachers as learners', International Journal of Instruction, 11(4), pp. 159-174. doi: 
10.12973/iji.2018.11411a.

Bergmark, U. (2020) 'Teachers' professional learning when building a research-based education: context-specific, collaborative and teacher-driven professional development', Professional Development in Education, 00(00), pp. 1-15. doi: 10.1080/19415257.2020.1827011.

Direktorat pembinaan sekolah menengah atas direktorat jenderal pendidikan dasar dan menengah kementerian pendidikan dan kebudayaan (2017) 'PANDUAN Implementasi Kecakapan Abad 21 Kurikulum 2013 di Sekolah Menengah Atas'. Jakarta: DIREKTORAT PEMBINAAN SEKOLAH MENENGAH ATAS DIREKTORAT JENDERAL PENDIDIKAN DASAR DAN MENENGAH KEMENTERIAN PENDIDIKAN DAN KEBUDAYAAN TAHUN 2017.

Gobena, G. A. (2018) 'Factors affecting in-service teachers' motivation: Its implication to quality of education', International Journal of Instruction, 11(3), pp. 163-178. doi: 10.12973/iji.2018.11312a.

Hofmann, D. A. (1997) 'An overview of the logic and rationale of hierarchical linear models', Journal of Management, 23(6), pp. 723-744. doi: 10.1177/014920639702300602.

Hwang, S. (2020) 'The Mediating Effects of Self-Efficacy and Classroom Stress on Professional Development and Student-Centered Instruction', International Journal of Instruction, 14(1), pp. 1-16. doi: 10.29333/IJI.2021.1411A.

Ismail, S. N. et al. (2018) 'Teacher collaboration as a mediator for strategic leadership and teaching quality', International Journal of Instruction, 11(4), pp. 485-498. doi: 10.12973/iji.2018.11430a.

Munoz, M., Prather, J. R. and Stronge, J. H. (2011) 'Exploring teacher effectiveness using hierarchical linear models', Planning and Chaning, 42(3/4), pp. 241-273. Available at: http://files.eric.ed.gov/fulltext/EJ975995.pdf.

Odebode, A. A. (2018) 'Influence of Psychosocial Factors on Job Performance of Female Teachers', International Journal of Instruction, 11(3), pp. 233-248.

Raudenbush, S. W. and Bryk, A. S. (2002) 'Hierarchical Linear Models: Applications and Data Analysis Methods.', in Advanced Quantitative Techniques in the Social Sciences. Second Edi. Thousand Oaks, California: SAGE Publications, Inc. doi: $10.2307 / 2290750$.

Stephens, P., Tønnessen, F. E. and Kyriacou, C. (2004) 'Teacher training and teacher education in England and Norway: A comparative study of policy goals', Comparative Education, 40(1), pp. 109-130. doi: 10.1080/0305006042000184908.

Subedi, B. R., Swan, B. A. and Hynes, M. C. (2013) 'Predicting Gain Scores with 
Hierarchical Linear Models: A Value-Added Approach to Measure Teacher Effectiveness', Journal of Studies in Education, 3(3), p. 149. doi: 10.5296/jse.v3i3.4187.

Suciati et al. (2019) 'The single-case research of coastal contextual learning media on the understanding of numbers counting operation concept', International Journal of Instruction, 12(3), pp. 681-698. doi: 10.29333/iji.2019.12341a.

Woltman, H. et al. (2012) 'An introduction to hierarchical linear modelling', Tutorials in Quantitative Methods for Psychology, 18(1), pp. 52-69. doi: 10.1002/(SICI)10970258(19990415)18:7<855::AID-SIM117>3.0.CO;2-7. 